\title{
DE KERKBESCHOUWING VAN PROF. DR. J. H. GUNNING
}

In Nederland zijn van de theologen uit de vorige eeuw in de laatste tijd de namen van DR. Kohlbrugge, Dr. Hoedemaker en DR. A. KUYYPER meer vermeld dan die van D. Chantepie de la Saussaye en Gunning. Dat wil niet zeggen dat de laatsten vergeten zijn, maar de aandacht werd meer op de eersten gericht. Ik heb reden van te veronderstellen dat dit hier in Pretoria ook zo is. Ik ben daarom dankbaar dat mij de gelegenheid werd gegeven om in dit uur iets over prof. GunNiNG te zeggen.

Gunning noemde zich graag een leerling van Daniel Chantepie de la Saussaye. Over La Saussaye schreef dr. A. M. Brouwer, later hoogleraar te Utrecht, zijn dissertatie. Over GunNing heb ik in 1926 de mijne uitgegeven.

LA Saussaye was eers Waals, dat is Frans sprekend, predikant te Leiden, daarna Ned. Herv. predikant te Rotterdam. (De Waalse Kerk behoort tot de Ned. Herv. Kerk, is deel van de Herv. Kerk). In 1872 werd hy tot hoogleraar benoemd in Groningen. Hij hield zijn oratie in November 1872, maar stierf onverwachts na een ziekte van een paar dagen reeds in Febr. 1874, 55 jaar oud. La SAuSSAYE heeft een eigen weg gevolgd onder de theologen in Nederland. Hy heeft zijn gedachten ontwikkeld in het tijdschrift Ernst en Vrede dat tussen 1850 en 1860 in 6 jaargangen uitkwam, in de Prot. Bijdragen die vanaf 1870 verschenen en in verschillende werken die hij uitgaf. Hij nam een tussenpositie in tussen de gewone orthodoxie en het opkomend modernisme en is daarom meermalen tot de Vermittelungstheologen gerekend. BROUwER noemde hem een Israelietisch denkend theoloog. Hij verzette zich tegen het intellectualisme dat hij bij rechtzinnigen en vrijzinnigen vond. Hij ging evenals PASCAL uit van het hart van de mens, of met A. VINET van la conscience. Het Franse woord conscience heeft een ruimere betekenis dan het Hollandse geweten. LA SAussaye heeft dat zelf wel eens vaker uit het oog verloren wanneer hij in het Hollands geweten schreef en aan conscience dacht. God spreekt den mens aan in zijn hart. GunNing gevoelde zich nauw verbonden met LA Saussaye. Hij was 10 jaar jonger. Geboren in 1829, heeft hij in Utrecht gestudeerd, werd predikant in Blauwkapel dichtbij Utrecht, dan in Hilversum; was van 1861 tot 1881 , dus 20 jaar predikant in den Haag, werd in 1881 benoemd tot kerklijk hoogleraar aan de gemeente-universiteit te Amsterdam en in 1889 tot rijkshoogleraar aan de rijksuniversiteit te Leiden. In 1899 moest hij wegens 70-jarige leeftijd aftreden en verhuisde naar Arnhem. Daar is hij als ouderling van de Herv. gemeente blijven voortwerken tot hij in 1905 is overleden -75 jaar oud.

GunNing heeft van 1855 tot 1905 gepubliseerd, zoveel dat zijn zoon vijf banden nodig had om met vele medewerkers verslag te geven van zijn 
Leven en Werken. Gunning schreef in Ernst en Vrede, in de Prot. Bijdragen, in de Stemmen van Waarheid en Vrede van dr. A. Bronsveld, en in vele andere tijdschriften, gaf brochure ens boeken uit, reageerde snel op alles wat hij las door ingezonden stukken te zenden voor dag- of weekbladen. Wie de theologie in Nederland in de 19de eeuw beschrijven en de naam van GunNing niet zou noemen zou wel zeer onvolledig zijn. Prof. S. P. EngelBRECHT noemt hem wel in zijn Kerkgeskiedenis.

GunNing was zeer veelzijdig. Hij had eigenlijk litterator willen worden. De Wijsbegeerte trok hom ook zeer. Prof. Opzoomer uit Utrecht beschouwde hem asl een van zijn beste leerlingen. ' $t$ Is aan zijn initiatief te danken dat GunNing in 1876 tot doctor honoris causa in de filosofie werd benoemd in Utrecht. Doctor theologiae is hij nooit geworden. Geen enkele Universiteit heeft er aan gedacht om hem die titel honoris causa te verlenen. Hy kende Homerus, Plato, Spinoza, Shakespear, vooral Dante en Thomas Aquinas, Schiller, Goethe als weinigen. Toen hij predikant was in den Haag maar ook later als hoogleraar hield hij telkens winterlezingen in den Haag over zeer verschillende onderwerpen. Verslagen van de meeste van die lezingen als ook van vele van zijn preken kan men in handschrift vinden in de Gunning Biblioteek die bij de rijksuniversiteitsbiblioteek van Utrecht is ondergebracht. GuNNING preekt van korte aantekeningen. Er zijn personen geweest in den Haag die een uitvoerig verslag maakten van zijn preken en lezingen, ook van de catechisaties die hij in het Frans hield voor een bepaalde groep leerlingen. Er zijn in de Gunning Biblioteek dikke banden vol van wat Gunning bij verschillende gelegenheden heeft gezegd in verslagen die niet zijn gepubliceerd.

Zijn kerkbeschouwing kwam al aan het licht toen hij in 1859 schreef over Gordel en Wijnkruik, gedachten over de zonde en hare ellende, over Jeremia 13:1-17, en in 1860, toen hij een beroep had gekregen uit de vrije evangelische gemeente te Amsterdam. Gunning schreef een Open brief aan de ouderlingen van die gemeente en gaf in 1861 een brochure uit over Vrijheid der gemeente. Een van zijn mooiste geschriften heet „Beginsel en meningen", in 1860 geschreven. Het is hier in de biblioteek. In verschillende brochuren kwam hij in verzet tegen het aandringen op leertucht door Mr. Groen van Pristerer met wie hij bevriend was, dien hij zeer hoog achte, maar dien hij niet kon volgen in zijn juridische denkwijse. In den Haag was nog vóor GunNing er kwam Dr. J. C. ZaAlberg predikant geworden in de Herv, gemeente. Hij was van de Evangelische of Groningse richting tot de vrijzinnige overgegaan. Hij hield een reeks lezingen in de geest van die Tubinger F. C. Baur. Groen van Prinsterer noemde dat anti-christelijkegodslastering en wilde dat die predikant zo spoedig mogelijk zou worden afgezet. Er was brand uitgebroken - die moest direct, worden geblust.

GunNing schreef een brochure: De kracht der waarheid tot overwinning ook op kerkrechtelijk gebied, of Twee wegen, éen doel. Hij had wel hetzelfde doel als Groen, dat in de kerk de Christus naar die Schrift 
zou worden gepredikt, maar hij wilde bij het correctief ingrijpen niet van buiten naar binnen, maar van binnen naar buiten gaan, van het leven naar de vorm die het zich schept. Wettelijkheid behoort alleen op het gebied van de staat thuis.

De grond, het recht moet aan de dwaling ontnomen worden. Het is een feit dat Gods immanentie in de leer van de Kerk te veel is verwaarloosd. Gods openbaring is in Christus menselijk geworden. De theologie moet waarachtig modern zijn. Antwoorden op de vragen en behoeften van nu. De theologie volgt de ontwikkeling in de kerk. Er is allereerst behoefte aan het leven des $\mathrm{H}$. Geestes daarna aan de beschrijving ervan. In de moderne richting zijn twee mogelijkheden: of men keert zich naar Christus toe of van Hem af. De ontwikkeling gaat nog voort. Het Evangelie vraagt vrije instemming, Gehoorsaamheid dat is meer een zaak van de wil dan van het intellect. Gaarne beriep GunNing zich op Joh. 7:17. „As iemand gewillig is om sy wil te doen, sal hy omtrent die leer weet of dit uit God is en of Ek uit Myself spreek," of op Joh. 5:40. ,En julle wil nie na My kom om die lewe te hê nie,”, of op Joh. 3:36. „Hy wat in die seun glo, het die ewige lewe, maar hy wat die Seun ongehoorsaam is, sal die lewe nie sien nie, maar die toorn van God bly op hom." Jesus heeft volgens Matth. 21:28vv. de gelijkenis uitgesproken van "die twee seuns.". „Maar wat dink julle? 'n Man het twee kinders gehad en hy gaan na die eerste en sê: Kind, gaan werk vandag in my wingerd. En hy antwoord en sê: Ek wil nie; maar later het hy spyt gekry en gegaan." Om tot geloof te komen is er verootmoediging nodig, erkenning van schuld, zien op Jezus Christus als den Middelaar Gods en der mensen. Hij heeft ons door Ziin kruisdood en opstanding verlost.

De Kerk moet hen, die zeggen niet te kunnen geloven, niet dadelijk uitwerpen, maar moet trachten hen te winnen. Men wint iemand vaak nog eerder voor 't geloof door goed voorbeeld dan door leer. (Beginsel en meningen (1860) bl. 69). Paulus heeft telkens aan zijn gemeenten geschreven: Weest mijn navolgers, broeders. Fil. 3:17. „Let op die wat so wandel soos julle ons tot voorbeeld het.” Petrus raadde de vrouwen aan: „Net so moet julle, vroue, aan jul eie manne onderdanig wees, sodat, as sommige aan die woord ongehoorsaam is, hulle ook deur die wandel van die vroue sonder woorde gewin kan word." GunNing was overtuigd dat hij ook woorden moest gebruiken. Hij hield niet op mondeling en schriftelijk te getuigen, te vermanen, tot bekering te roepen, maar hij zei dat uitbannen, wanneer noch hij die uitgebannen werd, noch de gemeente die uitbande vast overtuigd waren van het rechtmatige van die daad, niet was naars Here Wil. De Kerk verkeert in een vervallen toestand. Leefde voorgangers en gemeenteleden nog so vol van den $\mathrm{H}$. Geest als de eerste Christengemeente dan zou het anders zijn. De eigenlijke zonde is niet te bidden. In I Clem. 59vv. is een voorbeeld van oud-Chr. gemeentegebed. Helaas is er sedert het ophouden van de vervolgingen en het binnenlaten van de menigte onder Constantyn de Grote een daling gekomen van het peil van het Christelijk 
leven in de Kerk; uitzonderingen waren er gelukkig wel, maar over ' $t$ algemeen kan men zeggen dat toen het proces van verwereldlijking reeds is begonnen. Later is dat proces door de Renaissance, het humanisme, het buiten de Kerk treden van filosofie, wetenschap en cultuur nog versterkt. De Kerk is door daling van het geloofspeil zelf de oorzaak, minstens medeoorzaak, geweest van het afdwalen. De Kerk is er niet mee gered wanneer hier of daar een persoon word aangepakt, die haars insiens te ver is afgedwaald. $\mathrm{Zij}$ moet principieel positie nemen en al maar weer het licht van de openbaring doen schijnen over de aldoor wisselende gebeurtenissen en omstandigheden. Zoals Paulus door zijn brieven de gemeenten leiding heeft gegeven door te getuigen, te waarschuwen en te bevelen zo heeft de Kerk leiding te geven.

Wie moet leiding geven?

In de Oude Testament is de koning telkens voorgesteld als de herder van het volk. Jezus heeft volgens de Evangeliën telkens gesproken van het koninkryk Gods of het koninkryk der hemelen en heeft ons leren bidden: Uw koninkrijk kome. GunNING dacht dat wanneer Israel Jezus als de Messias had aanvaard, 's Heren koninkrijk sou zijn gesticht en niet de kerk. Petrus heeft op het Pinksterfeest, en in zijn redevoering en erna nog telkens, Israel opgeroepen tot bekering en tot geloof in Jezus als den Christus, den Messias, Koning.

Israel heeft den Messias niet willen aanvaarden. Toen heeft God de natuurlijke takken niet gespaard, zoals Paulus in Rom. 11:21 zegt, maar God is machtig om ze weer in te enten in den boom waarvan zij afgehouwen zijn. GunNing hoopte zeer op Christus wederkomst, $Z_{i j n}$ komen in heerlijkheid. Dan zou het koninkrijk komen. God had Israel vroeger geleid door personen, door profeten, priesters en koningen. Jezus heeft vgl. Luc. 22:30 Zijn apostelen beloofd dat zij de twaalf stammen Israels zouden oordeelen. Volgens Ef. 4:11 heeft Christus ook over de Kerk, waarvan $\mathrm{Hij}$ het hoofd is, personen aangesteld om haar te leiden: apostelen, profeten, evangelisten, herders en leraars . . zoals er staat, om die heiliges toe te rus vir hulle dienswerk tot opbouwing van die liggaam van Christus, totdat ons almal kom tot die eenheid van die geloof en van die kennis van die Seun van God tot 'n volwasse man en die mate van die volle groot te van Christus.

In Ef. 1:10 heeft Paulus gezegd dat die doel is om alle dinge wat in die hemele sowel als wat op die aarde is onder een hoof in Christus te verenig. Het moet worden een liggaam en een Gees, een Heer, een geloof, een Doop, een God en Vader van almal (Ef. 4:4). GunNiNg had al zijn hopen en verwachten gericht op de komst van den Bruidegom. Met Openb. 22:20 bad hij: Kom, Here Jesus. Ef. 5:25 Christus heeft die gemeente liefgehad en Homself daarvoor oorgegee om dit te heilig nadat $\mathrm{Hij}$ dit gereinig het met die waterbad deur die woord, sodat $\mathrm{Hij}$ die gemeente aan homself kan voorstel, verheerlik, sonder vlek of rimpel of iets dergeliks, maar dat dit heilig en sonder gebrek kan wees. Eens sal Hij ons ver- 
nederde liggaam van gedaante verander om gelykvormig te word aan Sy verheerlikte liggaam volgens die werking waardeur $\mathrm{Hy}$ ook alles aan Homself kan onderwerp (Fil. 3:21). Jezus zal bij zijn wederkomst vragen naar wat de nasies, de mensen uit de naties, gedaan hebben (Matt. 25:31vv). Heeft men barmhartigheid getoond als Jezus? De ranken van de wijnstok die geen vrucht voortgebracht hebben worden in ' $t$ vuur gegooid en verbrand (I Joh. 15:6). Gunning was overtuigd dat zij die met hun mond Here, Here zeiden en met hun verstand de orthodoxe leer beleden maar de wil van den Vader in den hemel niet deden, zouden verworpen worden, zoals Jesus het aan 't slot van de Bergrede heeft gezegd (Matt. 7:21-29). De Here wil gehoorzaamheid. Gehoorzaamheid is zaak van de wil. De Here vraagt meer naar de wil dan naar 'n begrijpen. Matt. 18:00 Kinderen zouden de volwassenen voorgaan. Matt. 11:25. Jezus dankte Zijn Vader dat het vir wijse en verstandige mense was verborgen, maar aan kindertjies geopenbaard. In het formulier om die Heilige Nagmaal te hou, staat terecht dat wij daagliks teen die swakheid van ons geloof en die bose luste van ons vlees moet stry, maar dat ons daarvan verseker kan wees dat geen sonde of swakheid wat nog teen ons wil in ons oorgebly het, kan verhinder dat God ons in genade sou aanneem.

Paulus heeft in zijn zelfveroordeling in Rom. 15vv onderscheiden tussen zijn wil en zijn doen. Wat ek doen, weet ek nie, want wat ek wil dat doe ek nie. Die wil is by my aanwesig, maar om goed te doen dit vind ek nie Jezus blust de rokende vlaswiek niet uit, maar blaast met zijn Geest aan wat versterven zou (Rom. 8). In Gethsemane heeft Hij tot zijn disipelen gezegd: Die gees is wel gewillig maar die vlees is swak (Matt. 26:41). Waak en bid dat julle nie in versoeking kom nie.

GunNing kende de verzoeking om met de z.g.n. Wetenschap mee te gaan. Gunnings vader, die predikant was in Leeuwarden, wilde hem niet voor zich laten preken, omdat hij te orthodox was voor de liberale gemeente daar. Zijn leermeester Prof. Opzoomer te Utrecht drong aan op empirée, ervaring, onderzoek. Mocht men een predikant die zich liet verleiden door geloofloze wetenschap (al was dit blind bijgeloof) dadelijk uitwerpen? GunNiNG trachte hen te overtuigen van de waarheid van het Evangelie.

In 1860 heeft hij in de lezing, in den Haag gehouden over Beginsel en meningen, die ik al aanhaalde, zich verzet tegen onheilige leerheiligheid en even onheilige waarheidsverkrachting, tegen intellectualisme van rechts of van links. De waarheid is zedelijk, eist een beslissing van de wil, vraagt verootmoediging, bekering. Gunning deed zijn intree in den Haag 14 Aug. '61 met Joh. 3:3. Voorwaar, voorwaar, Ek sê vir jou, as iemand nie weer gebore word nie kan hy die koninkryk van God nie sien nie. Hij zei in die intreepreek dat hij niet mee kon doen met hen die zeide: Wie niet aan de opstanding gelooft, kan onder ons geen leraar zijn. Men kanimmers niet tevreden zijn met te vragen wat hij gelooft, maar heeft bovenal te vragen hoe en waarom hij gelooft. De waarheid is persoonlijk. Jezus Christus is 
alleen de Waarheid. Ik hecht niet aan de hele of halve orthodoxie, maar aan de levensgemeenschap met den Heer. Het leven gaat voorop. Daarop volgt de kennis van het leven en de beschrijving ervan. Levensgemeenschap met den Heer blijkt nietuit dorre verstands godgeleerdheid maar in kracht Gods tot redding, in liefde en blijdschap, vrucht van den H. Geest.

GunNing achte de gemeente van nu te zwak van Geestes kracht om anders uit te kunnen bannen dan alleen door beroep op 't geweten, overtuigen van hem die afweek door woord of daad. I Cor. 14:24 schreef Paulus: Maar as almal profeteer en daar 'n ongelowige of 'n onkundige binnekom, dan word hy deur almal oortuig, deur almal beoordeel en so kom die geheim van die hart aan die lig. En so sal hy op sy aangesig val, God aanbid en verkondig dat God werklik onder julle is. Op andere wijze over de geheimen van iemands hart te oordelen, vond GunNing te gevaarlijk. Wat uit 'n geloof niet is, is zonde. Bij onzekerheid kan men beter wachten dan een verkeerde beslissing nemen.

GunNing wilde niet een belijdeniskerk, maar een belijdende kerk.

De jaren door heeft hij op reorganisatie van de Herv. Kerk aangedrongen. Het reglement in 1816 ingevoerd bepaalde wel dat men zich moest houden aan de leer der Kerk, maar gaf geen gelegenheid aan de classicale vergaderingen en de Synode om nieuwe beslissingen te nemen op grond van Schriften belijdenis. Allerlei voorstellen zijn er door GuNNING gedaan om verbetering aan te brengen. Zijn grote grief was dat de godsdienstige gemeenschap in een rechts gemeenschap was ontaard. Sedert 1890 toen GuNNING in Leiden een heel moeilijke positie had temidden van vrijzinnigen die beweerden dat alleen onbevooroordeelde, algemeengeldige wetenschap als wetenschap mocht worden gerekend, is Gunning met dr. HoEDEMAKER gaan medewerken tot reorganisasie van de Kerk.

Hozdemaker was meer conservatief dan GunNing, wilde meer de lijn van de Geref. vaderen voortzetten. Hij vond de Ned. Herv. Kerk de Kerk van Christus in Nederland.

Hij was predikant te Amsterdam, is van 1880 vanaf de oprichting van de Vrije Universiteit hoogleraar daaraan geweest, maar is wegens conflict met dr. A. KuYPER afgetreden en werd predikant in Nijland, een dorp in Friesland.

GunNing die het altijd voor verdrukten opnam ... hij is wel een ridder genoemd in het leraarskleed... gevoelde zich toen temeer tot HOEDEMAKER aangetrokken. In 1893 schreef hij in een brochure: Komt het op vroomheid des harten aan? (bl. 29). De Kerk behoort tot een organisatie te komen die het karakter van gelijken rang en gelijken waardigheid aan alle Evangeliedienaren toelaat. Want dan zal het Woord Gods feitelijk gelijk behoort, boven de Belijdenis staan. Dat Woord zal spreken in de wettiglijk vergaderde Dienaren des kerk en over de bestaande verschillen uitspraak doen. Die uitspraak, moet definitief voor alle tijden, maar voor onze tijd, is het allerdringendst belang der kerk. 
Al werkte Gunning zo met Hofdemaker samen de laatste 15 jaar van zijn leven, hij bleef meer op de algemene christelike Kerk zien, bleef hopen op Christus wederkomst, op het geloven van Israel. In 1902 schreef hij nog dat de Bruidegom de eenheid der Bruid nodig had, het Hoofd de eenheid van de lichaam. Ef. 4:11-16 bleef voor hem de norm. De Here heeft gegeven apostelen, profeten, evangelisten, herders en leraars... Niet een belijdenis moet heersen in de Kerk, maar ambtsdragers, personen, moeten leiding geven, bezield door het geloof. Karakter gaat boven belijdenis.

Christus wil niet dat iemand zal heersen in de Kerk, maar dat allen zullen dienen. Het kerkherstel moet eigenlijk ook internationaal geschieden. Subjectivisme en individualisme zijn te veroordelen. Wij hebben gemeenschappelijk schuld te belijden en gemeenschappelijk om Christus heerschappij in de kerk te bidden. Tucht is alleen mogelijk in de ene Kerk bij profetisch licht. Hij bleef vertrouwen op de kracht der waarheid tot overwinning. De rechts kracht van Gods Woord in de Kerk moest hersteld worden.

In 1896 gaf hij een rede uit over De eenheid der Kerk, in 1897 over Hooger dan de Kerk, in 1899 Blijft in Hem. In 1900 volgde de brochure De opbouw der kerk op haar grondslag. $1901 \mathrm{Niet}$ bij elkander houden maar uit den grond opbouwen, en Onze zonde. 1902 Om 's Heren heerschappij in de Ned. Hcrv. Kerk en Verlagen wij ons zelven niet. In 1904 De wortel des kuaads. Heel de Kerk en heel het volk, (dat was de leus van Hozdemaker), en Open brief aan de Synode der Ned. Herv. Kerk.

Wat zou GunNiNg gezegd hebben wanneer hij de reorganisatie van onze Nederl. Herv. Kerk die in 1945 begonnen, had kunnen beleven. De Kerk wil nu gaan in den weg van het belijden, wil zich houden aan de Heilige Schrift en de belijdenisgeschriften, wil zich voorlopig onthouden van leertucht, wil tot de gewetens spreken, wil trachten te overtuigen. Wat door 't geweten der gemeente niet beaamd wordt, blijft onvruchtbaar in de Kerk, 't gebrek des Geestes, zei GunNing.

Aan vele verlangens van Gunning is voldaan.

Maar het geesdriftig verlangen naar de wederkomst van Christus, en naar het herstel van Israel is niet algemeen. Niet altijd wordt ook zo sterk aan de algemene Christelijke Kerk, de una ecclesia catholica, het lichaam van Christus gedacht, als hij daaraan heeft gedacht. GunNing was een man van veel gebed, die veel verwacht van voorbede. Als 't er al op aankwam, konden wij niet veel meer doen dan bidden: Kom Here Jezus, Wees Gij onze Koning, Herstel Israel als uw volk en regeer ons allen naar uw rechtvaardige, zachte, lichte wet. Dan zullen allen delen in de zegen des Heren en de vrede van Gods volk sal ewig blijven.

De reorganisatie van onze Ned. Herv. Kerk is tot stand gekomen. Op initiatief van Dr. Gravemeyer, Prof. Kraemer en Prof. Banning, die elkander in het concentratiekamp in den oorlogstijd gevonden hadden. 
Prof. Haitjema, van Ruler, Miskotte, Scholten, ds. Wesseldijk en anderen hebben de Kerkorde uitgewerkt. Na onderzoek in de classicale vergaderingen is er veel in gewijzigd. In 1950 werd ze aangenomen en ingevoerd. Hier is men de weg gegaan die door GunNing en Hofdemaker was aangeraden, niet die van dr. A. Kuyper.

KUYPER was evenals GUNNiNg zoon van een conservatief liberale dominee. Hij heeft in Leiden gestudeerd onder prof. Scholten, die Hegeliaan was, die speculatieve richting uitging, niet de empirische, zoals OpzOMMER in Utrecht. In zijn eerste gemeente Beesd in Gelderland kwam KuYPER tot bekering. Hij oordeelde dat het Gereformeerd beginsel de Kerk zou redden. Hij ging in de lijn van Mr. Groen van Prinsterer door, werd diens opvolger als antirevolutionair partijhoofd. Van Beesd ging hij naar Utrecht in 1870 van Utrecht naar Amsterdam. Zijn intreetekst in Amsterdam was Ef. 3:17vv. Geworteld en gegrond. 't Was hem meer te doen om de schaapskooi dan om 't enkele schaap. KuYPER nam de belijdenis als woord van gemeenschap op grond van de onfeilbare Heilige Schrift. Hij pleitte voor een vrije Kerk en vrije school in het vrije Nederland... sedert 1880 ook voor een vrije Universiteit... scheiding van Kerk en Staat. Autonomie van de gemeenten ... vry beheer van de kerklijke goedere.

In $1871 \mathrm{kwam}$ hij ook in conflict. Hij was er heftig tegen dat de Kerkeraad vrijzinnige lidmaten zou aannemen. In 1885 weigerde de Kerkeraad attesten af te geven van zedelijk gedrag opdat de jongelui in een naburige vrijzinnige gemeente zouden kunnen worden aangenomen. 4 Jan. 1886 werden toen 80 kerkeraadsleden geschorst. Dec. 1886 wierp men van Kuypers zijde het juk der synodale hierachie af, en Jan. 1887 werd het eerste Geref. congres gehouden.

GunNing onderscheidde in KuYPER de Christen van het partijhoofd. Hij waardeerde hem als Christen, geniaal schrijver van overdenkingen over gedeelten van Gods Woord in de Heraut of de Standaard. Maar als partijhoofd vond hij KuYPER niet geestelijk, intellectualistisch. KuyPER wilde met logische consequentie de naam van Christus doen triumferen op elk terrein des levens. GunNING betrapte hem telkens op onoprechtheid, onwaarachtigheid, heerszucht.

Groen van Prinsterer had het reeds als vanzelfsprekend geacht dat wanneer men orthodox christen was, men ook lid moest zijn van de antirevolutionaire partij. D. ChANTEPIE DE LA SAussaye had zich al tegen dit nauwe verbinden van Kerk en Staatsidee verzet. Men had het recht niet om een Christen te binden aan een bepaalde staatsbeschouwing.

Kuyper ging nog verder dan Groen van Prinsterer. Hy schreef in de Standaard over De Heelen en de Halven. De heelen ware natuurlijk zij die hem volgde. Op de halven paste hij toe wat in 1 Joh. 2:19 is gezegd. Hulle het van ons uitgegaan, maar hulle was nie van ons nie, want as hulle van ons was, sou hulle by ons gebly het, maar dit moes aan die lig kom dat hulle nie almal van ons is nie. GunNing heeft het zich erg aangetrokken 
dat KUYPER hem zo openlijk bij de anti-christenen rekende van wie immers in 1 Joh. 2 was gesproken. Hij heeft vele jaren lang getracht om KuYPER tot andere gedachten te bewegen, maar dat is hem niet gelukt. KuYPER noemde zijn partij de partij van de lewende God, de Gideons bende die de vijanden in 's Heren naam zou overwinnen. Gereformeerd in de Kerk en anti-revolutionair in de politiek was naar zijn inzicht onlosmakelijk met elkander verbonden. Hij beriep zich voor alles wat hij ondernam op een tekst uit het onfeilbare Woord Gods. Zelf heb ik hem in mijn studententijd te Utrecht in Tivoli de invoering van de wet op de bakkers nachtarbeid horen verdedigen met een woord uit Hosea: De bakker slaapt de ganse nacht. De tekst is daar corrupt. Er is sprake van de koningen van Israel. Hos. 7:5v. In de Suidafrikaanse vertaling is de bakker er geheel uitgevallen. Daar staat: Op die dag van ons koning is die vorste siek van verhitting deur wyn. Hy steek sy hand uit na die spotters as hulle naderkom. Hulle hart is soos 'n oond in hulle arglistigheid. Die ganse nag deur slaap hulle toorn, in die môre vroeg brand dit soos 'n vuurvlam.

Dr. KUYPER was zo overtuigd van de juistheid van zijn visie dat zijn exegese er geheel door beheerst werd.

In zijn Encyclopaedie der christelijke theologie ... op zichzelf een geniaal werk... sprak hij van tweëerlei wetenschap. Zijn eigen wetenschap noemde hij die van de palingenesie. Wie wedergeboren was, moest oordelen als hij.

Kuyper was een schitterend volks-redenaar; hij werd altijd door zijn volgelinge luide toegejuigt; hij was ook een geniaal journalist. Hij publiceerde ongelofelijk veel. Hij had een overredingskracht waar velen niet tegen op konden. Hij heeft jarenlang als lid van de Tweede Kamer in den Haag gewoond, toen GuNNiNG daar predikant was, later in Amsterdam als professor aan de Vrije Universiteit, toen GunNiNG kerkelijk hoogleraar was geworden aan de Gemeente Universiteit te Amsterdam.

Zij moesten elkander telkens ontmoeten. GunNing wilde evenals HoEDEMAKer de volkskerk niet loslaten. Al was er veel zondigs in de kerk, al moest de kerk gereorganiseerd worden, afscheiding vond hij ongeoorloofd; afscheiding was de zonde van de Farizeeërs, die zeide God, ek dank $U$ dat ek nie soos die ander mense is nie. GunNing vond dat de Kerk de tollenaars niet mocht loslaten, maar met alle zondare schuld moest belijden en bidden: God, wees mij sondaar genadig. Het is jammer dat DR. KUYPER de afscheiding heeft doorgezet. Tijdens de laatste wereldoorlog heeft PRof. Schilder van Kampen in conflict met Prof. HePpe van de Vrije Universiteit te Amsterdam een nieuwe afscheiding doorgevoerd. Prof. ScHilder beschuldigde de Geref. Synode van hetzelfde waarvan DR. KUYPER vroeger de Hervormde Synode had beticht. Schilder nam Art. 31 van de Dordtse Kerkorde als leus voor zijn afscheiding. Deze afscheiding is ook al niet meer tot Nederland beperkt, maar is doorgegaan tot in Indonesië, Australië, misschien ook wel tot hier in Suid-Afrika, overal waar Synodaal Gereformeerden wonen. 
GunNing heeft zeer geleden onder het onophoudelijk veroordelen van de ethischen door KuYPER. Wat hij wil zal deze geestelijke Napoleon bereiken, schreef hij aan zijn zoon die als predikant te Gouda, sterk onder de bekoring van KuYPER was gekomen, maar voegde GUNNING eraan toe: evenals bij dezen zal zijn werk topzwaar worden en vallen. KuYPER handelt als een ongelovige. Op de kracht der waarheid heeft hij niet vertrouwd; politiek en verdachtmaking moest er bij komen. Ik heb nooit als Bronsveld op zijn hatelijkheid, enz. gewezen, neen, deze behoren bij zijn door en door wereldsch streven. Daardoor heeft hij dan ook macht. W'ant de wereld, en niet het minst als zij gereformeerd is, heeft het hare lief en loont het met macht, invloed en middelen.

Het willen heersen van Rome vond hij ook bij KuYper. Elk goed militair of partijhoofd doet hetzelfde als Rome ... De waarheid behoeft macht, zeggen ze. De godsdiens heerse als Kerk, als organisatie, als goed gesloten kader.

GuNNING heeft alle afscheidingen betreurd. Zijn verlangen ging uit naar de ene, ,heilige' algemene christelijke Kerk die zich voorbereidt voor de wederkomst van haar Heer. Op Hervormingsdag kon hij treuren over het gebrek aan eenheid.

Hij is gestorven (in 1805) voordat de grote wereldconferenties worden gehouden. De Evangelische Alliantie vond hij te bepaald Engels, te weinig Protestants Evangelisch. GunNing hield niet van de Engelsen als volk, zegt zijn zoon. Den oorlog van Engeland tegen de twee Afrikaanse Republieken vond hij gruwelijk, een verkrachting van alle recht. Hij vond het een verlaging tot geweld, leugen en beestelijke wreedheid. De naaste drijfveer was gewetenlose gouddorst (L.\&.W. III 542v). Laat ons de Engelsen niet haten, schreef hij in de Berichten, het Studentenblad, 16 Nov. 1899, toen hij als gepensioneerden te Arnhem was gaan wonen. Alleen door onder het kruis te komen en daar de afschuwelijkheid ook onzer eigen zonden te leren kennen, worden wij van de haat genezen en kunnen wij ook de Engelschen leren liefhebben en voor hen bidden. Uit dat gebed moet, zal het niet voor God een gruwel zijn, alle schijnheiligheid en de hoogmoed, die daar achter schuilt, door diep besef van ons aller verdoemlijkheid voor God zijn weggedaan. Eenig en alleen de Heilige Geest kan dit leren en die vlam des haat tegen de zonde met de vlam der liefde van Christus in ons samenvoegen tot een gloed die al het vleeschelijke in ons verteert.

In 1902 schreef GunNing nog: Voor mij is niet de Hervormde Kerk het ideaal, maar de ene algemene Kerk des Heren. Ik geloof ook niet dat een geschreven belijdenis grondslag der Kerk kan zijn, maar enkel de levende personen door den Here gesteld (Ef. 4). GunNing wilde daarom eerst reorganisatie. Christus werkt in de Kerk door zijn ambtsdragers, om die heiliges toe te rus vir hulle dienswerk tot opbouwing van die liggaam van Christus. Opbouw van het lichaam van Christus was GunNing 's enige doel. Gunning is trouw gebleven aan een woord dat hij in 1860 al heeft 
geschreven (Beginsel en meningen bl. 91): 't Is noodzakelijk om niet bij de geloofsovertuigingen en uitdrukkingen onzer vaderen te blijven staan, maar vanuit hun beginsel (alle waarachtig geloof heeft slechts een beginsel) hun overtuigingen en meningen te herzien, te verbeteren en verder te ontwikkelen.

Later heeft GunNing duidelijker dan in 1860 gezien dat dit de kerk moet doen in haar wettige vertegenwoordiging, geleid door den Heilige Geest.

In Supplement to Vetus Testamentum Vol. III 1955, te Leiden uitgegeven, komt PROF. GEMSER na een uitvoerige studie over 't Hebr. w.w. „rieb” met wat hiermee samenhangt, tot de conclusie dat men in het Oude Testament ondogmatisch, onsystematisch denkt. Alles is ten slotte overgelaten aan den hoogsten Rechter en Koning, wiens oordeel rechtvaardig is, maar ondoorgrondelijk voor 's mensen begrip. $\mathrm{Hij}$ is een Persoon, niet een systeem of orde. Dit houdt in dat er beroep mogelijk is op Hem, zelfs een irrationeel beroep op zijn hart zijn medelijden, zijn genade. Rom. 11:32v. God het hulle almal in die ongehoorzaamheid ingesluit om almal barmhartig te kan wees.

Diepte van die rykdom en wysheid en kennis van God. Hoe ondeurgrondelik is Sy oordele en onnaspeurlik Sy weë.

J. H. SEMMELINK. 